\title{
The Conceptual Structure for a Depletion of Global Warming through Proficient Reforestation in South East Asia
}

\author{
C. Vanlisuta
}

\begin{abstract}
The objective of this paper is to determine the number and species of plants to be planted in order to maximize a profit through an integer linear programming model. In addition, this paper tends to reveal detailed data of a number of carbon equivalent emitted in the country which is about $375,662,000$ tons per year. This amount is equivalent to 1.0 percent of the total number of carbon equivalent in the World. A large number of organizations therefore collaborate on enhancing forest by growing plants in the natural parks in order to reduce enormous amount of carbon dioxide. However, the forestation method is varied depending upon available plants and social community preference. As a result, the clean mechanism is not fully effective. No research literature in terms of which and how many plants should be grown to reduce certain amount of carbon dioxide is available. Let alone considers a mathematical model to solve this formidable problem. The conceptual idea will be presented in this paper. This framework can be a guideline for the government to promote effective forestation strategy or any party who are interested to maximize carbon credits by growing various plants under certain constraints.
\end{abstract}

Index Terms -Mitigate carbon, optimization, mathematical, integer programming.

\section{INTRODUCTION}

Greenhouse gases (GHGs) or global warming becomes a serious threat and concern to human beings nowadays. This problem is aggravated until almost every nation in the World agrees to reduce carbon emission to the atmosphere. As a result, the Kyoto Protocol is ratified and a three-market based mechanism including emission trading, clean development mechanism, and joint implementation are main effective antidote.[1] The United Nations Framework Convention on Climate Change (UNFCCC) elaborated that the clean development mechanism (CDM), defined in Article 12 of the Kyoto Protocol, allows emission-reduction projects in developing countries to obtain certified emission reduction (CER) credits, each equivalent to one metric ton of $\mathrm{Co}_{2}$ [2], [3]. These CERS can be traded and used by industrialized countries to meet a portion of their emission reduction target. Thailand also had ratified UNFCCC in December 1994 and later ratified Kyoto Protocol in August 2002 [4], [5].

The afforestation and reforestation are the key pertinent methods in order to reduce GHGs in the atmosphere.

Manuscript received May 15, 2014; revised July 10, 2014

C. Vanlisuta is with the Department of Production Engineering at Phranakhon Rajabhat University, Bangkok, Thailand (e-mail:c.vanlisuta@gmail.com).
However, the forestation know-how in terms of which and how many plants should be planted so that the exact amount of $\mathrm{Co}_{2}$ can be met is not yet available. This paper aims to present the conceptual research framework to optimize both different kinds and number of plants in a certain area based on various constraints whereas the by-product revenue is also taken into accounted. The expected result can be used by the government, institutions, and private sectors as formula to maximize emission reduction credits and return on investment from their forestation activities.

Afforestation is a conversion process that basically changes croplands to forest by growing a variety of trees. Reforestation is a process of restoring trees from lands that used to be forest or burned lands that cannot regenerate without intervention. This will not include a process of planting trees immediately to replenish after harvest according to U.S. EPA (Environmental Protection Agency). These practices expedite carbon sink through carbon sequestration. However, the sequestering rate is different. The carbon sequestration rate in U.S. by afforestation is about 0.6-2.6 metric tons of carbon per acre per year and the reforestation practice contributes around 0.3-2.1 metric tons of carbon per acre per year [2]. The period of sequestration lasts around 90 to 120 years before saturating. After reaching a saturation point, additional carbon accumulation is no longer possible. Although the trees are fully matured, a forest practice is still needed to sustain the accumulated carbon and prevent the losses of carbon back to the atmosphere. It is obvious that the afforestation and reforestation are the key strategic factors to reduce GHGs in the atmosphere. The fruitful period takes year and years and continues up to over 100 years. Therefore, it is of important to carefully plan and manage forest plantation to attain high yield with utmost efficiency. Thus, the mathematical model is one of the most viable tools to improve forest management.

Based on the report of Office of Natural Resources \& Environmental Policy and Planning under the Ministry of National Resource and Environment, the greenhouse gases are emitted around $350,611,000$ tons by 5 sectors in 2004 as shown in figure 1 . The energy, land-use change sector is accounted for $69 \%$ and $24 \%$ respectively. The rest are industrial, agriculture, and wastes. Furthermore, the emission projection of GHGs in Thailand by 2010 will be $375,662,000$ tons per year as shown in figure 2 . The total of 12 government sectors, and institutions, as well as 30 private sectors collaborate in the afforestation and reforestation activities. Each of them persuades people to plant trees or join the promotion in the business activity. However, as 
mentioned earlier, the forest management is not efficient due to a lack of research in this field [6].

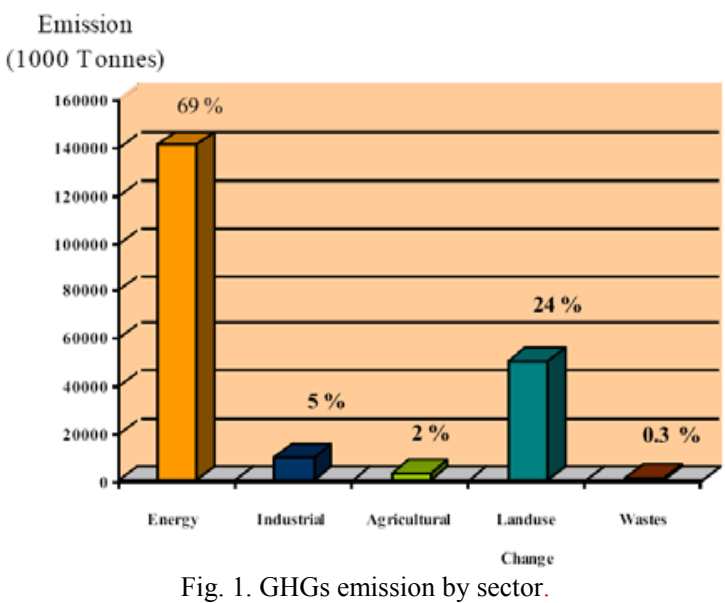

Source of information: National Clean Development Mechanism Study for the Kingdom of Thailand (2002) [7].

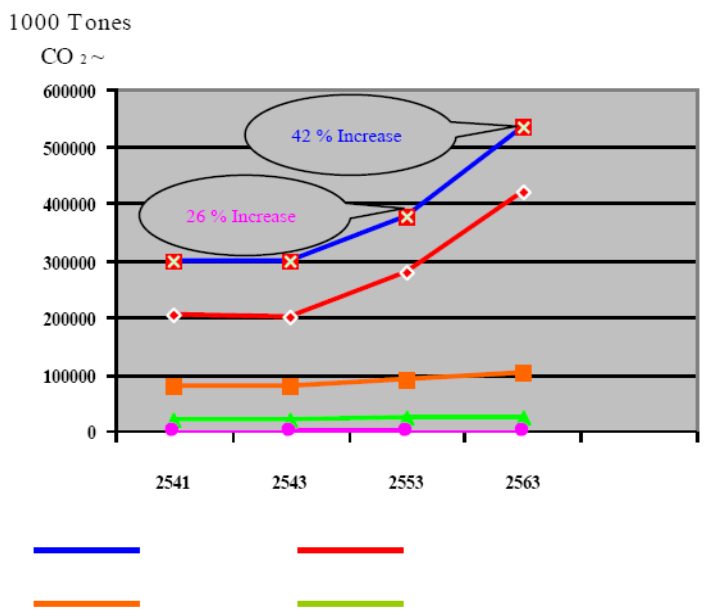

Fig. 2. Projection of Thailand greenhouse gases emission (based on emission data in 2004)

\section{Methodology}

\section{A. Methodology}

The forestation requires amalgamation of different kinds of knowledge and techniques. The state-of-the-art includes a selection of an appropriate tree based on local climate, the condition for growth, growth characteristics of the tree species, carbon sequestration rate, density of the tree's wood, planting and maintenance costs etc. In addition, the cost-effectiveness of reforestation is one of the essential issues to be considered. In order to maximize the return on investment, the optimization approach, therefore, is proposed to solve this problem. [7] The integer linear programming technique is implemented to f a mathematical model.[8]-[9]

\section{B. Optimization Model}

The proposed optimization model is composed of the objective function and constraints and can be shown as follows:

\section{The Objective Function}

This function aims to maximize the return which derived from the difference between revenues from emission trading and expenses of forest plantation. The objective function can be expressed as follows:[10]

$$
\text { Max. } Z=\sum_{i=1}^{n}\left[X_{i}\left(C a_{i}-b_{i}\right)\right]
$$

whereas $X_{i}$ is a number of plants grown in the forest. C defines as carbon trading income per metric ton of carbon; $a_{i}$ is the average amount of carbon sequestration in metric ton per year; $b_{i}$ is the total expenses of planting and maintenance plants per year where $i$ is the tree species.

\section{Constraints}

The objective function is subjected to the following constraints.

1) Area constraint: The summation of appropriate areafor each tree must not greater than the available forest area.

2) Carbon sequestration constraint: The total amount of carbon sequestration by all plants must greater than the minimum expected amount of carbon absorbed.

3) Nonnegative constraint: The number of plants must greater than zero and be an integer.

The above constraints can be expressed as (2) to (4) as follows:

$$
\begin{aligned}
& \sum_{i=1}^{n} 1_{i} X_{i} \leq L \\
& \sum_{i=1}^{n} a_{i} X_{i} \geq S \\
& X_{i} \geq 0 \text { where } i=1,2, . . n
\end{aligned}
$$

whereas $1_{i}$ is the required area for a tree needed to grow. $L$ is the available land area and $\mathrm{S}$ is the required amount of carbon to be offset by plants.

It is obvious that there are several parameters involved, and they play an important role in the model. One of the most important parameters is a carbon credit trading. According to the report of World Bank, the trading price was 7.5 -11.0 $\$$ per ton carbon dioxide equivalent in the year 2007. [11]-[12] Therefore, in this paper, the trading price is assumed 11.0 $\$$ per ton carbon dioxide equivalent. The carbon credit increases profit in the model. On the other hand, expenses of planting and maintenance a tree including land preparation, seeding, fertilizing and so on decrease profit.[13] These expenses can be summarized in Table I. It is obvious that these expenses are varied only in the first year due to different seeding cost [14].

\section{E. Amount of Carbon Sequestered By a Tree}

As mentioned previously, individual tree has different capability to sequester carbon based on its species. Therefore, research on how to measure the amount of carbon sequestered by plants must be performed. A few 
algorithms are proposed to calculate the amount of carbon sequestered.[15]-[16] As an example, The National Computational Science Leadership Program explains the method by calculating the green and dry weight of a tree. Then, find the weight of carbon in a tree by multiply 0.5 to the dry weight of the tree. After that the amount of $\mathrm{Co}_{2}$ sequestered can be calculated by multiply 3.663 to the amount of carbon in the tree. By this way, we can approximate the amount of carbon dioxide absorbed by plants form the atmosphere. This data is vital to the mathematical model. In this research framework, the amount of carbon dioxide absorbed by each interested tree must be calculated. Some of available data pertaining to tropical rainforest plants is depicted in Table II [17].

TABLE I: EXPENSES OF Planting AND MAINTENANCE A Plant WITH 7 YEARS

\begin{tabular}{|c|c|c|c|c|}
\hline \multirow{2}{*}{ Index } & \multirow{2}{*}{ Scientific Name } & \multicolumn{2}{|c|}{ Expenses(\$) } & \multirow{2}{*}{ Total } \\
\hline & & Year 1 & Years 2-7 & \\
\hline \multirow[t]{2}{*}{1} & Tectona grandis Linn. & 85.33 & 514.67 & 600.00 \\
\hline & Anogeissus acuminate & 73.76 & 514.67 & \\
\hline 2 & Pterocarpus macrocarpus & 80.67 & 514.67 & 588.43 \\
\hline 3 & Kurz. & 50.00 & 514.67 & 595.34 \\
\hline \multirow[t]{2}{*}{4} & Azadirachta indica A. Juss. & & & 564.67 \\
\hline & Var. siamensis(Valeton) & 93.83 & 514.67 & \\
\hline 5 & Swietenia macrophylla King. & 99.33 & 514.67 & 608.50 \\
\hline 6 & Sindora siamensis Teijsm. & 83.77 & 514.67 & 614.00 \\
\hline 7 & Lagerstroemia calyculata & 100.43 & 514.67 & 598.44 \\
\hline \multirow[t]{2}{*}{8} & Kurz & & & 615.10 \\
\hline & Xyliaxylocapa(Roxb.)Tuab.var. & 84.17 & 514.67 & \\
\hline 9 & Kerrii & 83.83 & 514.67 & 598.84 \\
\hline \multirow[t]{2}{*}{10} & Dalbergia oliveri Gamble & & & 598.50 \\
\hline & Delonix regia (Bojer) Raf. & & & \\
\hline
\end{tabular}

TABLE II: THE CARBON SEQUESTERED BY A PLANT

\begin{tabular}{clc}
\hline \hline Index & Scientific Name & Span (m.) \\
\hline 1 & Tectona grandis Linn. & $3 \times 3$ \\
2 & Anogeissus acuminate & $4 \times 4$ \\
3 & Pterocarpus macrocarpus Kurz. & $2 \times 2$ \\
4 & Azadirachta indica A. Juss. Var. siamensis(Valeton & $1 \times 2$ \\
5 & Swietenia macrophylla King. & $4 \times 4$ \\
6 & Sindora siamensis Teijsm. & $2 \times 2$ \\
7 & Lagerstroemia calyculata Kurz & $2 \times 2$ \\
8 & Xyliaxylocapa(Roxb.)Tuab.var. Kerrii & $2 \times 4$ \\
9 & Dalbergia oliveri Gamble & $4 \times 4$ \\
10 & Delonix regia (Bojer) Raf. & $2 \times 2$ \\
& & \\
\hline
\end{tabular}

\section{F. The Expenses of Plantation and Maintenance}

The expenses incurred can be divided into 2 phases. The first phase is the first year of plantation and the latter phase is during $2^{\text {nd }}-7^{\text {th }}$ years. [18] The relevant expenses involved each phase can be listed as follows:

First Phase ( $1^{\text {st }}$ year)

Land restoration and preparation

Seedling

Fertilizer

Surveillance and fire prevention trail

Labor cost

Miscellaneous

Second Phase $\left(2^{\text {nd }}-7^{\text {th }}\right.$ years $)$

Replenish unfruitful seedling

Fertilizer
Labor cost

Miscellaneous

The above expenses must be calculated and researched to obtain the data since this data must be included in the model [19], [20].

\section{G. The Expenses of Plantation and Maintenance}

Each tree requires a certain amount of areas for it to efficiently grow and stays healthy. The minimum required areas of the tree must be identified. This ensures that the tree can fully develop its branches and sequesters high carbon in the atmosphere around it. Some of research data pertaining to the required tree span is shown in Table III or Fig. 3 [21].

TABLE III: THE CARBON SEQUESTERED BY A PLANT

\begin{tabular}{clc}
\hline \hline Index & Scientific Name & $\begin{array}{c}\text { Absoption } \mathrm{CO}_{2} \\
\text { (Unit: lbs. per year) }\end{array}$ \\
\hline 1 & Tectona grandis Linn. & 278.37 \\
2 & Anogeissus acuminate & 305.90 \\
3 & Pterocarpus macrocarpus Kurz. & 8.86 \\
4 & Azadirachta indica A. Juss. Var. & 13.86 \\
& siamensis(Valeton) & 143.16 \\
5 & Swietenia macrophylla King. & 115.94 \\
6 & Sindora siamensis Teijsm. & 367.08 \\
7 & Lagerstroemia calyculata Kurz & 183.54 \\
8 & Xyliaxylocapa(Roxb.)Tuab.var. Kerrii & 193.02 \\
9 & Dalbergia oliveri Gamble & 321.20 \\
10 & Delonix regia (Bojer) Raf. & \\
& & \\
\hline \hline
\end{tabular}

Absoption $\mathrm{CO}_{2}$ (Unit: lbs. per year)

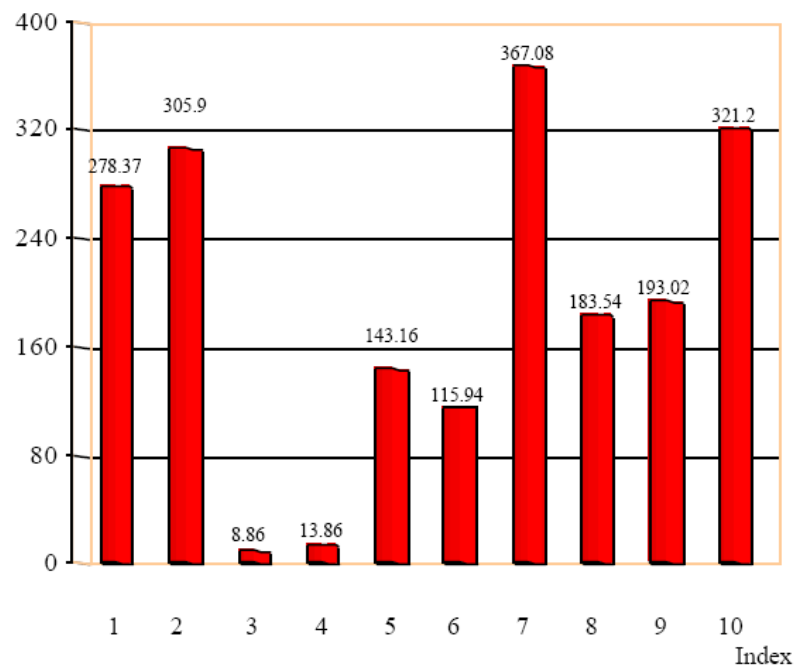

Fig. 3. The carbon sequestered by a plant.

\section{DISCUSSION}

A forestation and reforestation are the viable clean development mechanism to reduce GHGs and sustain the clean environment. The global warming due to GHGs brings to world attention. The optimization technique is one of the efficient methods to solve the engineering problem. It can be applied to various applications. Nevertheless, a selection of tree species in order to maximize the return from forest while fulfilling carbon absorb has not yet been addressed by the optimization technique. A great deal of research effort to obtain data must be done. This paper attempts to improve 
systematic reforestation in the future.

This paper demonstrates the utilization of the optimization technique to determine a number and type of trees to be planted in the forest in order to maximize profit. It will be useful for any organization who wants to grow plants and ensure obtained amount of carbon credit.

\section{REFERENCES}

[1] A. ClarkIII, J. R. Saucier, and W. H. McNab, "Total-tree weight, stem weight, and volume tables for hardwood species in the southeast," Research Division, Georgia Forestry Commission, p. 40, 1986.

[2] R. A. Birdsey, "Regional estimates of timber volume and forest Carbon for fully stocked timberland, average management after final clearcut harvest," Forests and Global Change, Washington, DC, vol. 2, 1996.

[3] M. P. Cigran and P. Iturregui, "Institutional Strategy to Promote the Clean Development Mechanism," UNEP Riso Centre, Denmark, p. 64, 2004.

[4] C. F. Cooper, "Carbon storage in managed forests," Canadian Journal of Forestry Research, vol. 13, pp. 155-166, 1983.

[5] M. Dutschke and L. Pedroni, Potential of Transaction-Cost Reduction by Simplified Modalities and Procedures and Measures to Facilitate Implementation of Small-Scale AR CDM Activities, Bonn, 2004.

[6] D. F. Huang, "Preliminary study on power structure optimization of Zhejiang province with message model," Energy Engineering, pp. 6-9, 2006.

[7] IIED National Resource Issues Paper, Laying the Foundations for Clean Development: Preparing the Land Use Sector, A Quick Guide to the Clean Development Mechanism, The Russel Press Ltd, Nottingham, NG6 OBT. p. 39, 2002.

[8] IPCC, IPCC Guidelines for National Greenhouse Gas Inventories: Reference Manual, Chapter 5: Land Use Change and Forestry, 1996.

[9] M. K. Lee, CDM Information and Guidebook, Second Edition Developed for the UNEP Project Cd4cdm UNEP Riso Centre, Denmark, p. 100, 2004

[10] K. Levin and J. Pershing, "WRI Issue Brief: Climate Science 2007Major New Discoveries," World Resources Institute, Washington, DC, 2008.

[11] Z. X. Li, Optimization and Adjustment of the Electrical Energy Structure of Hunan Province on the Circular Economy Stratagem, Changsha University of Science and Technology, 2007.
[12] F. Lin, The Regulation Economic Analysis of Optimizing Chinese Power Mix Structure, Shandong University, 2007.

[13] N. Myers and T. J. Goreau, "Tropical forests and the greenhouse effect: a management response," Discovery Bay Marine Laboratory, University of the West Indies, Discovery Bay, Jamaica, 1992.

[14] Y. Y. Qi and X. G. Ma, "Analysis of energy-saving potential and adjustment of industrial structure of shanghai," Energy Research and Information, pp. 1-4, 2007.

[15] L. Puangchit, Greenhouse Gas Inventory Forestry Sector, Kasetsart University, Bangkok, Thailand, p. 28, 2000.

[16] A. R. Birdsey, "Carbon storage and accumulation in united states forest ecosystems, general technical report W0-59," United States Department of Agriculture Forest Service, Northeastern Forest Experiment Station, Radnor, PA, 1992.

[17] J. Saucier and A. ClarkIII, Southwide Energy Committee, American Pulpwood Assosiation Inc, 1985.

[18] S. D. Wald, S. Josiah, and B. Erdkamp, "Heating with wood: producing, harvesting and processing firewood," University of Nebraska-Lincoln Extension, Institute of Agriculture Forest Service, Northeastern Natural Resources, 2005.

[19] Thailand Environment Institute, Thailand's Country Study on Climate Change 1990: Mitigation Options, Climate Change Scenarios, Vulnerability and Adaptation, Office of Environment Policy and Planning, Bangkok. Thailand, 1988.

[20] Y. L. Shi, Optimization of Electric Power Source Structure under the Constraint of $\mathrm{CO}_{2}$ Emission, North Chaina Electric Power University, pp.142-145, 2008.

[21] H. W. Zhang and Z. G. Niu, LINGO 8.0 and its Application to the Optimization of the Environmental System, Tianjin University Press, 2005.

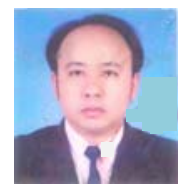

Chanchai Vanlisuta is a lecturer at Faculty of Industrial Technology, Phranakhon Rajabhat University, Thailand. He received a doctoral degree from the Graduate School of Engineering at King Mongkut' $s$ University of Technology Thonburi, His teaching and research interests include work study and planning and control production. 